\title{
Dose-Escalated Radiotherapy for the Treatment of Patients With Recurrent Colorectal Cancer
}

\author{
Hyung Jin Kim, Seong Taek $\mathrm{Oh}^{1}$ \\ Department of Surgery, St. Vincent's Hospital, College of Medicine, The Catholic University of Korea, Suwon; ${ }^{1}$ Department of Surgery, Seoul \\ St. Mary's Hospital, College of Medicine, The Catholic University of Korea, Seoul, Korea
}

\section{See Article on Page 66-72}

Local recurrence rates have markedly decreased in recent years as a result of changes in the surgical approach, such as a total mesorectal excision, as well as, neoadjuvant therapy for, the treatment of patients with colorectal cancer. For the treatment of patients with recurrent rectal cancer, a curative surgical resection of the local recurrence is considered the most important factor affecting the prognosis. However, such a resection is highly challenging as the surgical field has generally been anatomically disrupted and irradiated, and the tumor is typically adherent to or invasive into organs in the middle and low pelvis. And, such a resection is not always possible for all patients with recurrent rectal cancer, so the proper selection of patients for the surgery is very important [ 1 , 2]. If an $\mathrm{R} 0$ resection is impossible, chemotherapy or radiotherapy may be offered.

In terms of optimizing radiotherapy, the tumors should receive a high total dose while sparing the surrounding normal tissue to avoid toxicity. Dose escalation has also been suggested as possibly being of benefit in the treatment of patients with rectal cancer [3]. Development of new radiotherapy techniques, such as three-dimensional conformal radiation therapy, intensity-modulated radiation therapy, and image-guided radiation therapy, has made feasible the delivery of higher doses of external beam radiation with acceptable morbidity. However, if the patient has previously undergone radiotherapy either before or after the primary rectal cancer surgery, determining the proper dose of radiation is chal-

Correspondence to: Seong Taek Oh, M.D.

Department of Surgery, Seoul St. Mary's Hospital, College of Medicine, The Catholic University of Korea, 222 Banpo-daero, Seocho-gu, Seoul 06591, Korea

Tel: +82-2-2258-6100, Fax: +82-2-595-2822

E-mail: stoh@catholic.ac.kr

(C) 2016 The Korean Society of Coloproctology

This is an open-access article distributed under the terms of the Creative Commons Attribution NonCommercial License (http://creativecommons.org/licenses/by-nc/4.0) which permits unrestricted noncommercial use, distribution, and reproduction in any medium, provided the original work is properly cited. lenging because the surrounding normal tissues may have already received doses near the organ- or endpoint-specific tolerance dose during the primary treatment [4]. Because re-irradiation for the treatment of patients with recurrent rectal cancer is mostly given with hyperfractionated (twice daily) chemoradiotherapy to a total dose of 30-40 Gy [4], dose-escalated radiotherapy usually can be performed only for those patients who have not previously undergone radiotherapy.

The authors reviewed the records of patients who had been treated with palliative radiotherapy for locally recurrent colorectal cancers [5]. They reported that salvage radiotherapy, especially dose-escalated radiotherapy, for the treatment of such patients might be beneficial in that it might reduce the risk of progression. However, complete responses are rarely achieved even with high doses radiotherapy, and as expected, in this study, with one exception, dose-escalated radiotherapy was only offered to patients with no history of previous radiotherapy. In a clinical setting, the distinction between curative and palliative intent is often not clear and may depend on whether the patient is eligible for a curative resection after radiotherapy. Therefore, patients with recurrent rectal cancer should undergo adequate re-evaluation and have repeated discussions with a multidisciplinary team on topics such as dose-escalated radiotherapy, chemotherapy and surgical resection.

\section{CONFLICT OF INTEREST}

No potential conflict of interest relevant to this article was reported.

\section{REFERENCES}

1. Moriya Y. Treatment strategy for locally recurrent rectal cancer. Jpn J Clin Oncol 2006;36:127-31.

2. Yeo HL, Paty PB. Management of recurrent rectal cancer: practical insights in planning and surgical intervention. J Surg Oncol 2014;109:47-52.

3. Gérard JP, Azria D, Gourgou-Bourgade S, Martel-Laffay I, Hen- 


\section{Coloproctology}

nequin C, Etienne PL, et al. Comparison of two neoadjuvant chemoradiotherapy regimens for locally advanced rectal cancer: results of the phase III trial ACCORD 12/0405-Prodige 2. J Clin Oncol 2010;28:1638-44.

4. Guren MG, Undseth C, Rekstad BL, Brændengen M, Dueland S,
Spindler KL, et al. Reirradiation of locally recurrent rectal cancer: a systematic review. Radiother Oncol 2014;113:151-7.

5. Jo S, Choi Y, Park SK, Kim JY, Kim HJ, Lee YH, et al. Efficacy of dose-escalated radiotherapy for recurrent colorectal cancer. Ann Coloproctol 2016;32(2):66-72. 